\section{THE ACOUSTIC EFFECTS OF THE AUDIENCE IN THE MODERN USE THE OF ANCIENT THEATRES}

\author{
Gino lannace*, Amelia Trematerra \\ Department of Architecture and Industrial Design, Second \\ University of Naples - Borgo San Lorenzo, 81013 Aversa (Ce), \\ Italy
}

Article history

Received

20 June 2016

Received in revised form

2 January 2018

Accepted

15 February 2018

Published online

3 June 2018

*Corresponding author gino.iannace@unicampania.it
Graphical abstract

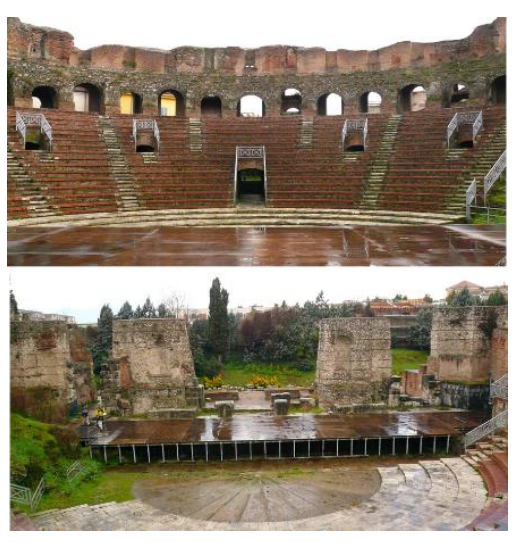

\begin{abstract}
The ancient theatres are used in modern age for different kinds of shows. Today the ancient theatres have been returned to be the center of cultural activities during the summer seasons. Although many shows do not achieve the success of the critics and of the audience due to the weak acoustics of the theatres. Often the audience criticizes the acoustics, because they consider them lacking for the spoken comprehension and for the weakness of the music. An important aspect is the presence of the audience in the cavea, so it is important to understand whether this has a negative role in the overall acoustics of the theatre. The presence of the audience in the cavea involves variations of the room's acoustics characteristics. The acoustic measurements are very difficult to carry out when there are people in the theatre. So it is possible to simulate the presence of the audience, in a virtual way, by using a software for architectural acoustics, in which the presence of the audience is simulated changing the value of the absorption coefficient of the surfaces of the cavea. The analysis of the numerical simulations show that the influence of the audience on the acoustics of theatres varies depending on the geometry of the theatre, and by the fraction of area of the cavea occupied by the audience.
\end{abstract}

Keywords: Acoustics, ancient theatres, audience, cavea, reverberation time

(C) 2018 Penerbit UTM Press. All rights reserved

\subsection{INTRODUCTION}

Today the ancient theatres are used for different kinds of events for examples plays, concerts, operas. Figure 1 shows the main architectural components of the ancient theatre: the stage (scena), the orchestra, and the cavea. The ancient theatres of Greek or Roman period, usable for various kinds of performances, are the result of a long process of excavation and restoration lasted many years, with the reconstruction of part of the stage, of the cavea and of the perimeter walls. The Greek theatres were built on the ridges of the hills, while the Roman theatres, built during the Imperial Age, were set inside the cities and they were built in bricks that they were composed of a series of arches. The theatres reached their greatest magnificence during the Roman imperial age (the cavea covered with marble and the stage adorned with plasters and columns) [1-3]. The theatres over centuries were destroyed by earthquakes and they were looted or demolished to use their materials to build palaces, churches, defensive walls and other construction works. Today the ancient theatres have been returned to be the center of cultural activities during the summer seasons. Although many shows do not achieve the success of the critics and of the audience due to the weak acoustics of the theatres. The present work aims to analyze the effects on the acoustics of ancient theatres, in modern use, with the presence of the audience sitting in the cavea [4-6]. The acoustic characteristics were measured in the restored theatres of Cassino, Taormina, Pompeii and 
Benevento. The acoustic measurements were carried out without the audience, by placing a spherical omnidirectional sound source on the stage (in the actor positon) and with the measurement microphones placed on the steps of the cavea, with a constant pitch, in order to obtain the average spatial values of the acoustic characteristics. The measurements have been done according to the ISO (ISO 3382) and the monaural acoustic parameters considered are $T_{30}, E D T, C_{80}$ and $D_{50}$. For the evaluation of the effects of the audience in the cavea on the acoustic parameters, was used a virtual model by the software for architectural acoustics "Odeon", because it is not possible performing acoustic measurements during theatre performances in presence of the audience. The software adopts a 3D virtual model of the theatre to analyze and returns the desired acoustic parameters. The first phase is the calibration procedure, this procedure uses the average value of the $\mathrm{T}_{30}$ measured as the referring acoustic parameter; and the values of the absorption coefficient to the virtual surfaces of the model are assigned. So the values of the $T_{30}$ calculated (obtained processing the software "Odeon") is equal to the values of the $\mathrm{T}_{30}$ measured. Finally for the evaluation of the presence of the audience on the acoustic parameters, the values of the absorption coefficient of the audience found in the literature are replaced to the values of the absorption coefficient of the cavea covered by bricks [7-9]. The considered theatres are the Roman theatre of Cassino, the Greek-Roman theatre of Taormina, the Greek-Roman theatre of Pompeii and the Roman theatre of Benevento, these theatres stay in South of Italy.

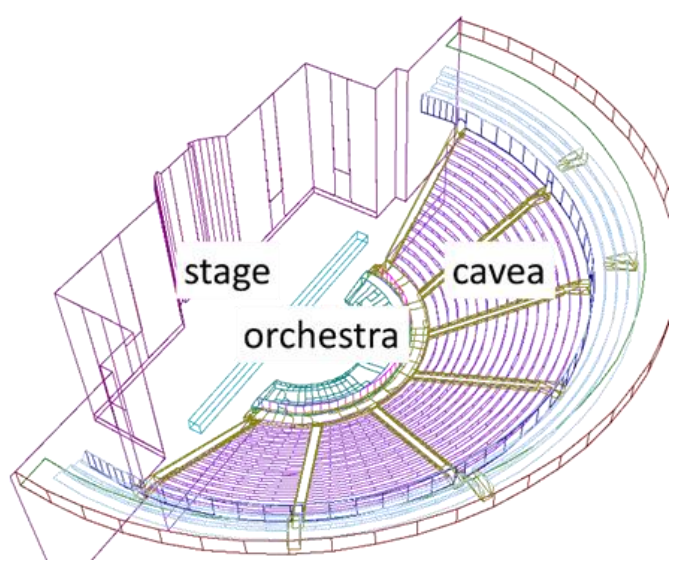

Figure 1 Main component of the ancient theatre

The Roman theatre of Cassino was built in the middle of the Augustan period in first century B.C. Subsequent historical events led it to being abandoned and eventually demolished. Over the centuries, several structures were built inside the theatre. The restoration work was completed in 2000, with only a few parts of the ima cavea remaining of the original theatre. The cavea stands on the slope of a hill and is oriented to the south-east, with semicircular steps and orchestra pit. It was originally divided into an ima and summa cavea. Today only a part of the ima cavea having been rebuilt. In its current state, the theatre has the following dimensions: orchestra diameter: $9.2 \mathrm{~m}$; cavea outside diameter: $46.0 \mathrm{~m}$; the stage building is $27.4 \mathrm{~m}$ long and $5.0 \mathrm{~m}$ wide; steps rebuilt in stone and mortar, with height of $0.4 \mathrm{~m}$ and depth of $0.7 \mathrm{~m}$; number of steps along the cavea are 19. The current capacity is about 3,000 spectators. During the summer, the theatre is used for several events, such as plays and various types of concerts. The acoustics of the theatre cannot be considered satisfactory due to the absence of a vertical wall on the stage [10]. Figure 2. A shows a view of the Roman theatre of Cassino, while Figure 2.B shows the virtual model by the architectural software Odeon.

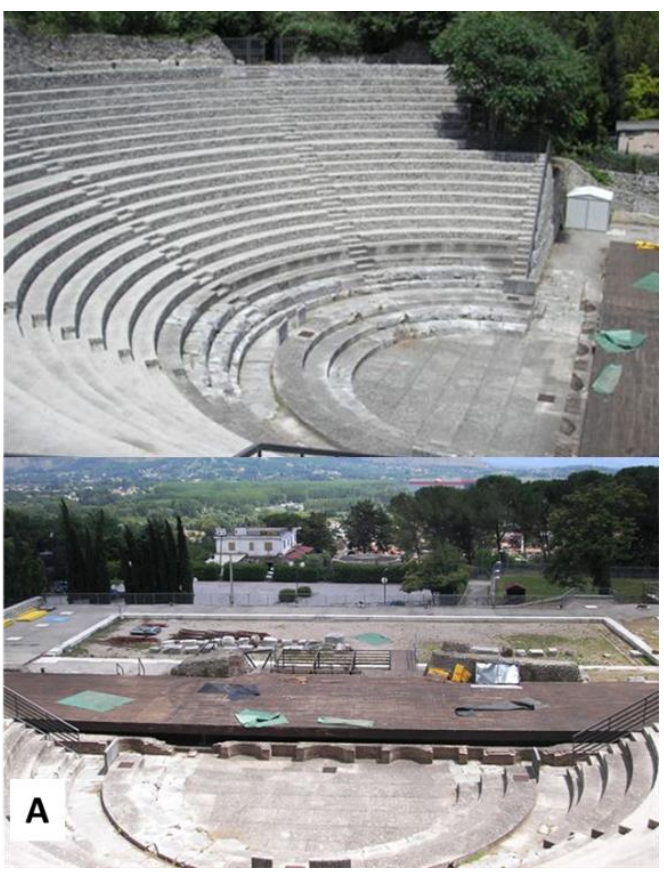

Figure 2 (A) View of the Roman theatre of Cassino

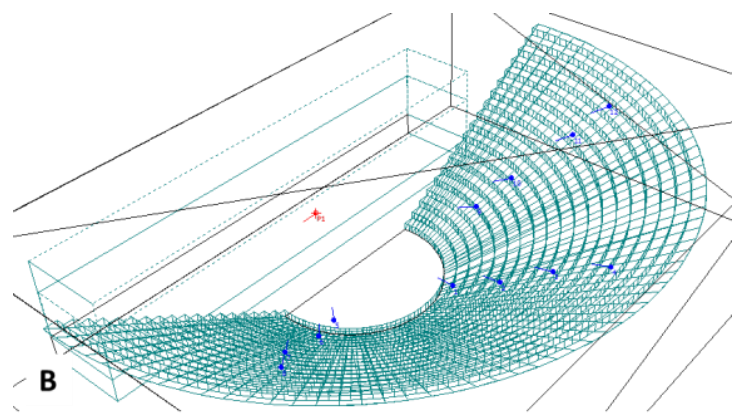

Figure 2 (B) Virtual model in Odeon

The theatre of Taormina there is not a thorough study about this, it was built at the end of the third century B.C., with the cavea resting on the hill. The 
diameter of the cavea is about $110.0 \mathrm{~m}$, the orchestra with an elongated U-shaped plant has a diameter of $35.0 \mathrm{~m}$, the stage building is $70.0 \mathrm{~m}$ long and $20.0 \mathrm{~m}$ wide. The theatre has been undergone renovations and expansions with the construction of a summa cavea and with the stage building connected to the cavea. In the 2 nd century B.C. the theatre was transformed into an amphitheatres and it was used for gladiator combats, chariot races, venationes (animal hunts) and executions. Today the cavea is partly rebuilt with bricks of terracotta. The theatre is used for different types of shows: opera, drama, dance and symphonic, jazz and pop music concert. The maximum capacity of about 4,500 spectators [11]. Figure 3. A shows a view of the Greek-Roman theatre of Taormina, while Figure 3.B shows the virtual model by the architectural software Odeon.

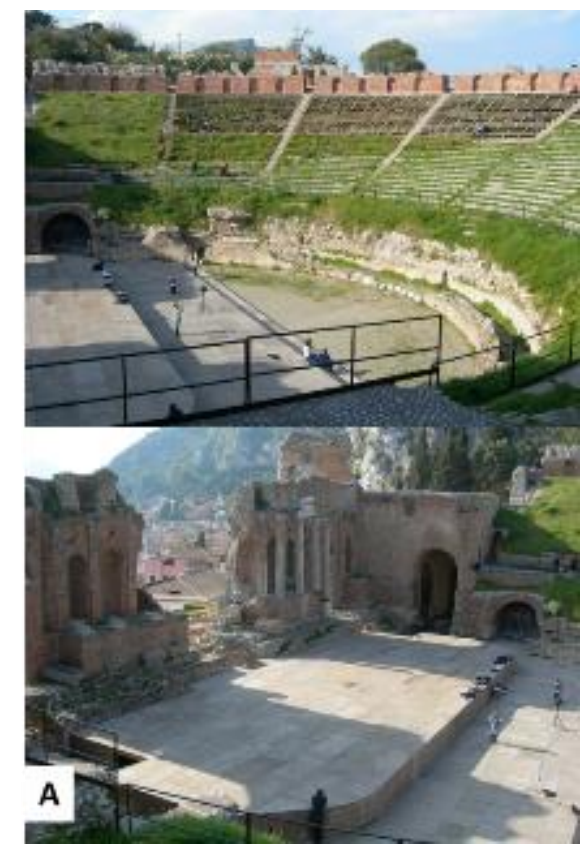

Figure 3 (A) View of the Greek-Roman theatre of Taormina

The theatre of Pompeii was built around 2nd century B.C. and is in part resting on the slope of a hill; the cavea has a diameter of $58.0 \mathrm{~m}$ (divided into ima and summa cavea) and the orchestra with a form of " U" shaped elongated, with a diameter of $11 \mathrm{~m}$ [12]. The stage building is $30.0 \mathrm{~m}$ long and $10.0 \mathrm{~m}$ wide, with a pulpit of $1.0 \mathrm{~m}$ high, and it was the subject of a second remake in the Augustan age. The cavea was divided into 3 parts, with the stage building, the realization of the summa cavea and the stage that was united to the cavea, creating a closed sideways building.

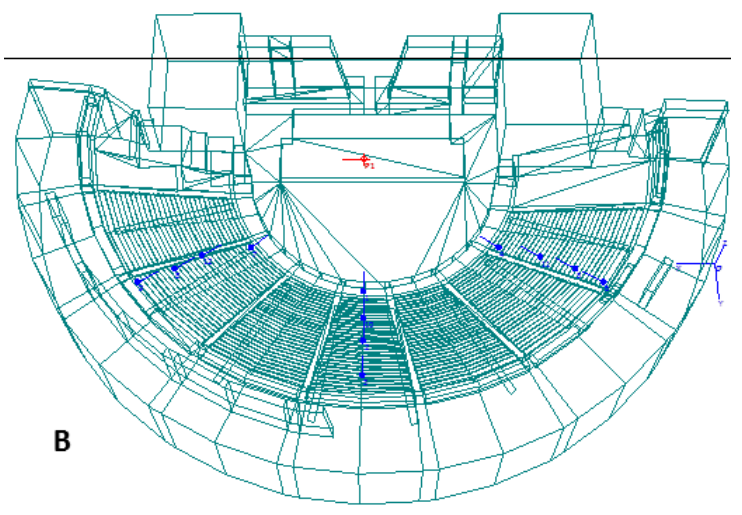

Figure 3 (B) Virtual model in Odeon

After the earthquake of 62 A.D., the theatre has been undergone to a further restoration work which involved the stage building [13]. The theatre was buried in 79 A.D. by the eruption of the Vesuvius and was unearthed in 1739. In recent decades, the theatre was used for events and shows; since the cavea was made of grass and hard court, there were placed some wooden planks on metal supports fixed to the cavea covered with earth and grass to allow to the viewers watching the performances until 2009. The theatre recently had a substantially renovation, completed in 2010, which affected the whole cavea, that was covered in squared blocks of tuff, steps height $0.4 \mathrm{~m}$ and depth of $0.7 \mathrm{~m}$; with a maximum capacity of about 1,800 spectators. The theatre actually is used during the summer season. Figure 4.A shows a view of the Greek-Roman theatre of Pompeii, while Figure 4.B shows the virtual model by the architectural software Odeon.

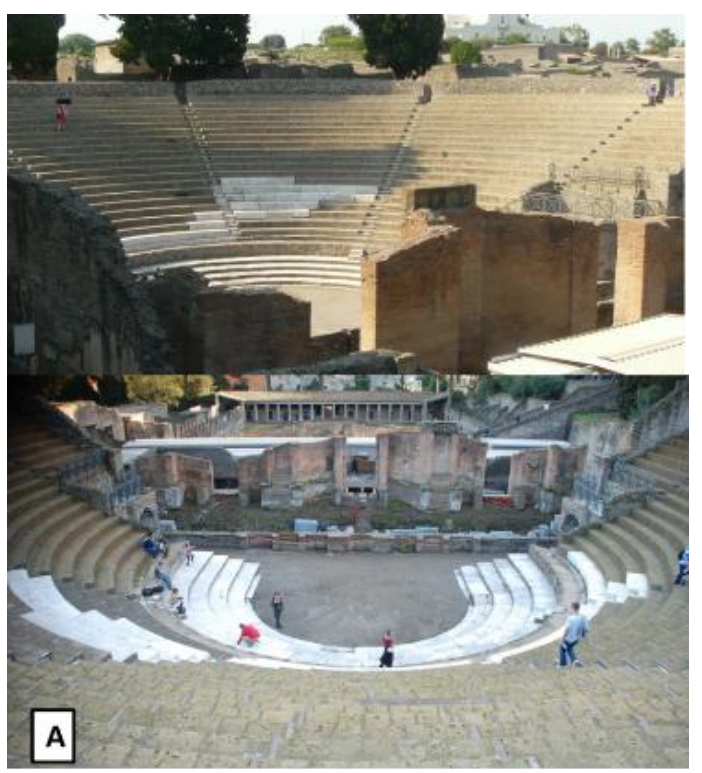

Figure 4 (A) View of the Greek-Roman theatre of Pompeii 


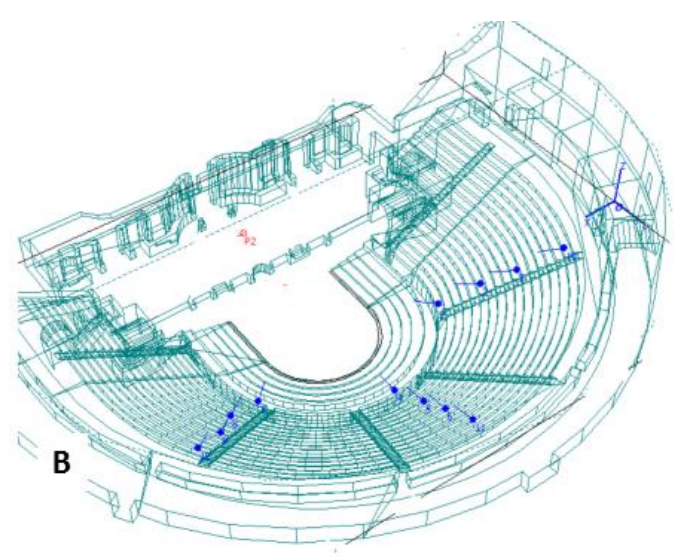

Figure 4 (B) Virtual model in Odeon

The theatre of Benevento was built during the imperial age, during the Trajanic period and it was inaugurated in 126 A.D. and enlarged by Caracalla between 200 and 210 A.D.. In origin it contained over 10,000 spectators; with a semi circular orchestra of $30.0 \mathrm{~m}$ of diameter, the cavea has a diameter of 98.0 $\mathrm{m}$ (divided into ima and summa cavea), the stage building is $44.2 \mathrm{~m}$ long and $3.5 \mathrm{~m}$ wide and is higher than the orchestra of about $1.5 \mathrm{~m}$. The theatre was abandoned after the barbaric invasion: the material was used for the construction of the city walls and to decorate churches and palaces. Over the centuries in the cavea were built some houses that were demolished in 1930 to rebuild the cavea and a part of the columns of stage building, only the church (Santa Maria della Verita) built in 17th century, over a part of the cavea, has survived. The ima cavea was rebuilt with bricks of terracotta, while the summa cavea was only partially rebuilt and it is not accessible to the audience. The theatre began to be used for events since 1950. Actually of the Roman theatre has the maximum capacity of about 1,800 spectators, and remains only fifteen steps of height $0.4 \mathrm{~m}$ and depth of $0.7 \mathrm{~m} \mathrm{[14]}$. The theatre is used for different types of shows: opera, drama, dance and symphonic, jazz and pop music concert. Figure 5.A shows a view of the Roman theatre of Benevento, while Figure 5.B shows the virtual model by the architectural software Odeon.

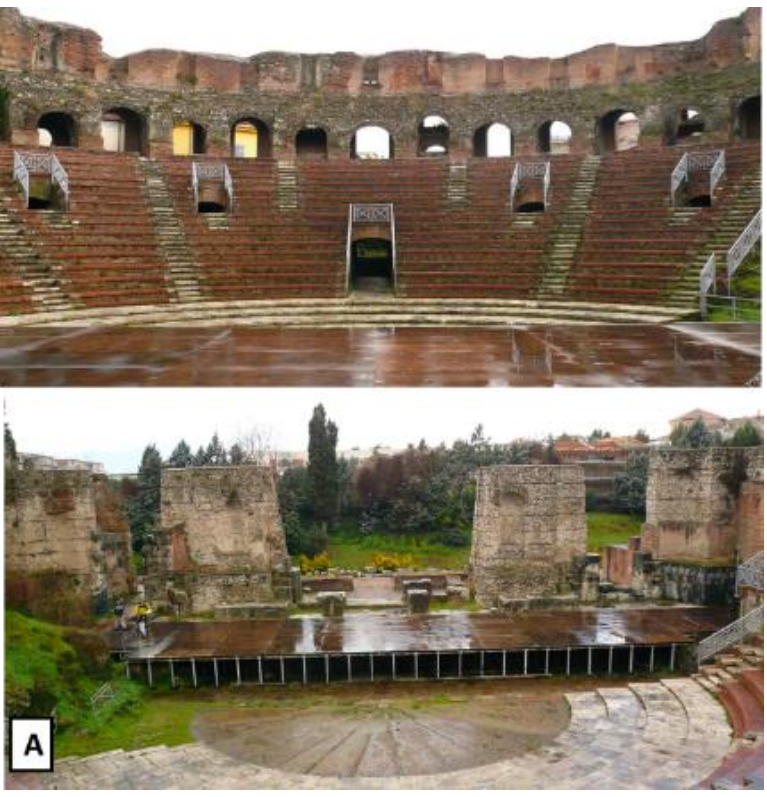

Figure 5 (A) View of the Roman Theatre of Benevento

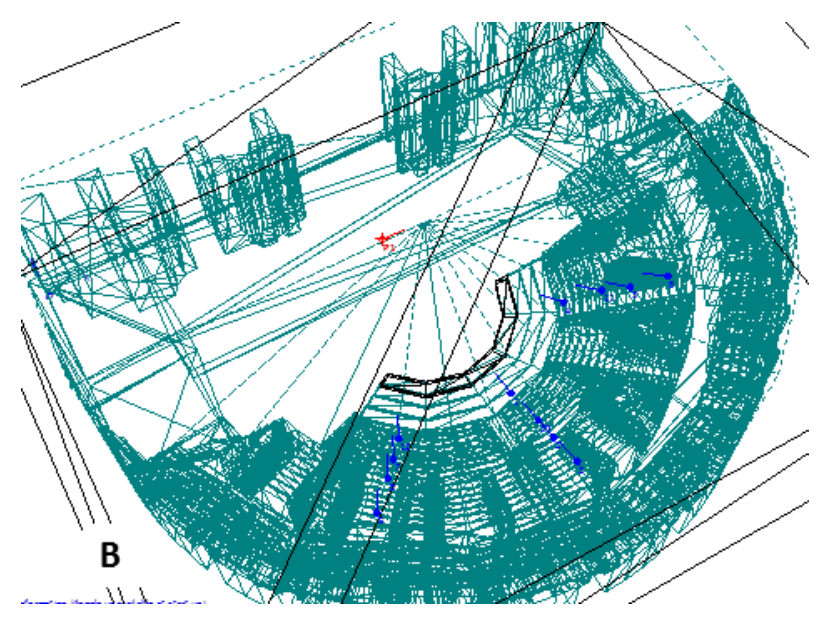

Figure 5 (B) Virtual model in Odeon

\subsection{METHODOLOGY}

\subsection{Acoustic Measurements}

The acoustic characteristics of the theaters were measured in situ by placing an omnidirectional sound source on the stage in the central area (in the actor position). 
The instrumentation used to perform acoustic measurements was constituted of a dodecahedron loudspeaker Peeker Sound JA12 and a power amplifier KT 150. MLS signals of order 16 (5 s) were generated by a $01 \mathrm{~dB}$ Symphonie system. The impulse responses were detected by a microphone type GRAS 40 AR 1/2". The impulse responses have been analyzed with the software Dirac 4.0. The microphone receivers were placed on the steps of the cavea with a fixed pitch along three radial directions, one central and two laterals, in order to obtain the average spatial values of the acoustic parameters of the theatres. The acoustic measurements were carried out without audience, while the theatres were empty. The acoustic measurements were carried with the method of the impulse response, the monaural acoustic parameters analyzed in accordance with the ISO (ISO $3382,2012)$ : are $T_{30}, E D T, C_{80}$ and $D_{50}$ in octave bands from $125 \mathrm{~Hz}$ to $4000 \mathrm{~Hz}$ [15-18]. Figure 6 shows the average value of $T_{30}$ measured in the Roman theatre of Cassino, in the Greek-Roman theatre of Taormina, in the Greek-Roman theatre of Pompeii and in the Roman theatre of Benevento. Analyzing the results it is possible to note a low value of the reverberation time not greater than 1.0 second at the frequency of 1.0 $\mathrm{kHz}$. This low value of the reverberation time is due to the absence of the walls of the stage house (which are only partially present). The cavea is in part reconstructed and the surfaces of the cavea are covered with bricks of terracotta and for this reason they have a sufficient high value of the absorption coefficient, the summa cavea is partially reconstructed too. The low value of the reverberation time is the main cause of the dissatisfaction of the audience who watches the performances.

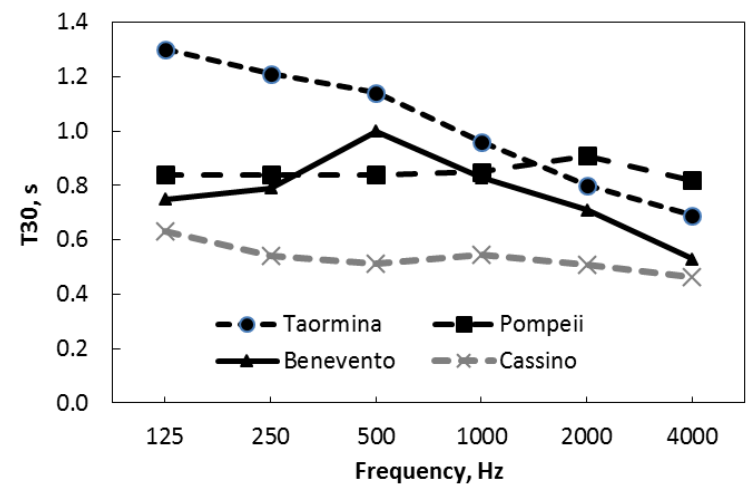

Figure 6 Average value of $\mathrm{T}_{30}$ measured in theatre of Cassino, Taormina, Pompeii and Benevento

\subsection{Numerical Simulations with Virtual Models}

A virtual model was simulated using the architectural acoustics software Odeon [18, 19]. The software Odeon imports the virtual model realized by a 3D cad. The virtual models were designed in 3D by applying the Vitruvio's rules for achieving a correct vision and listening of a theatrical play, and by the analogy with other Roman theatres and by geometrical measurements made in situ [20]. Furthermore the model of the software Odeon requires knowledge of the acoustic properties of the surfaces which made up the theatre. The software Odeon uses the principles of geometrical acoustics and adopts a hybrid calculation method that combines two classical methods, image source and ray-tracing method. The Odeon software uses a hybrid calculation method, where early reflections are calculated by combining the image- source and a ray tracing method. The late reflections are calculated using a ray tracing process, which generate diffuse secondary sources. In this process rays are sent from the source position detecting image sources up to a certain reflection order and then detecting secondary sources on the surfaces of the room. The secondary sources radiate with a directivity that follow Lamberts Law and an intensity contribution attenuated mainly by the distance and the reflections in the path from source to receiver. The transition order (T.O.) at which the calculation method changes from image-source to ray tracing can be adjusted according to the complexity and shape of the room. If T.O. is set to 0 the calculation method used for all reflections will be the secondary source / ray tracing method. The first postprocessing step consisted of comparing the acoustic measurements in the current state with the results obtained from the virtual model. This allowed to adjust the virtual model until obtaining simulated results as close as possible to those measured. The process consisted of minimizing the differences between the calculated and measured values of $T_{30}$ by tuning the absorption coefficients of the room surfaces. The goal was to reduce the difference between the simulated and measured values of $\mathrm{T}_{30}$ below $5 \%$. The acoustic model calibration is the first step and it is made by setting the absorbent coefficient values for all virtual model surfaces and the scattering coefficients. The scattering coefficients are related to the geometrical characteristics of the surface and not to the frequency. The seating rows were modelled with a scattering coefficient of $s=0.7$, while the stage wall and floor were assigned a scattering of $s=0.5$. In the virtual model, the receiving points were positioned along three radial directions of the cavea and in the same locations where the microphone was placed during the acoustic measurements, while the sound source was only placed on the stage (in the actor position). In order to assign material properties, some considerations about the materials of the theatre were necessary. The cavea and stage of the ancient theatres were made of hard materials such as stones. The absence of roofing was simulated in the virtual model by assigning an open roof. This means that the model of the theatre was closed in a box with an absorption coefficient equal to 1.0 assigned to the boundaries, to simulate outgoing propagation of the sound in an open-air space. Based on previous experience the calculations were performed by fixing set-up parameters impulse response length $=3,000 \mathrm{~ms}$ with a resolution $=3.0 \mathrm{~ms}$; number of late rays $=$ 
100,000 . The monaural acoustic parameters analyzed are: $T_{30}, E D T, C_{80}$ and $D_{50}$. Table 1 shows the values of absorption coefficients used in the virtual model for the cavea, in the four different theatres. After the calibration procedure, there were considered the values of the absorption coefficient of the audience in the cavea, this values have been reported in the literature. Table 2 shows the audience absorption coefficient used in the virtual model.

Table 1 Values of absorption coefficients used in the virtual model for the cavea, in the three different theatres

\begin{tabular}{ccccccc}
\hline $\begin{array}{c}\text { Frequency, } \\
\mathbf{H z}\end{array}$ & $\mathbf{1 2 5}$ & $\mathbf{2 5 0}$ & $\mathbf{5 0 0}$ & $\mathbf{1 0 0 0}$ & $\mathbf{2 0 0 0}$ & $\mathbf{4 0 0 0}$ \\
\hline Benevento & 0.48 & 0.40 & 0.30 & 0.40 & 0.54 & 0.72 \\
\hline Pompeii & 0.15 & 0.18 & 0.20 & 0.35 & 0.35 & 0.40 \\
\hline Taormina & 0.40 & 0.25 & 0.35 & 0.40 & 0.40 & 0.16 \\
\hline Cassino & 0.005 & 0.01 & 0.01 & 0.01 & 0.01 & 0.01 \\
\hline
\end{tabular}

In the virtual models the absorbent coefficients of the bricks of terracotta of the cavea have been replaced with absorbent coefficients of the audience. The comparison between the average acoustic parameters obtained by numerical simulation when the cavea is empty and with the presence of audience are reported. Figure $6(A, B, C, D)$ for the theatre of Cassino. Figure $7(A, B, C, D)$ for the theatre of Taormina. Figure $8(A, B, C, D)$ for the theatre of Pompeii. Figure $9(A, B, C, D)$ for the theatre of Benevento.

Table 2 Audience absorption coefficient used in the virtual model

\begin{tabular}{ccccccc}
\hline $\begin{array}{c}\text { Frequency, } \\
\mathbf{H z}\end{array}$ & 125 & 250 & 500 & 1000 & 2000 & 4000 \\
\hline Audience & 0.51 & 0.64 & 0.75 & 0.80 & 0.82 & 0.78 \\
\hline
\end{tabular}

\subsection{RESULTS AND DISCUSSION}

The numerical simulations were performed both with the empty theatres and with the presence of the audience, then the results of the two configurations were compared [21, 22]. The more reflective and diffusing surfaces remains of the building stage, the walls around the stage and the orchestra; this surfaces have been unchanged between the condition without and with the audience [23-25]. The Roman theatre of Cassino has not the walls on the stage, so the acoustic is very poor. In fact the $T_{30}$ is about 0.55 seconds, while with the audience the $\mathrm{T}_{30}$ is reduced to 0.50 second. The values of EDT are low because the first sound reflections do not arrive on the cavea. The examination of the numerical simulations (reported for the theatre of Taormina in Figures 6 and for theatre of
Pompeii in Figure 7) show that for these theatres the presence of the audience has a significant influence on the average values of acoustic parameters. The area engaged by the audience is $70-80 \%$ of the entire area of the cavea. The greatest effect appears for the energy descriptors at low frequencies, especially for EDT, in fact this parameter evaluates the first energy reflected by surfaces. The $T_{30}$ values are very low and the absence of important sound reflections cause a poor music or the voice actors on the stage isn't understood with a consequent dissatisfaction of the audience who watches the performances. Instead for the theatre of Benevento (Figure 8), the differences are appreciable in medium frequency bands. The variation of the absorption coefficient caused by the presence of the audience is relatively small, in fact for security reasons related to the escape in case of danger, the area engaged by the audience is only a fraction, about $50 \%$ of the entire area of the cavea.

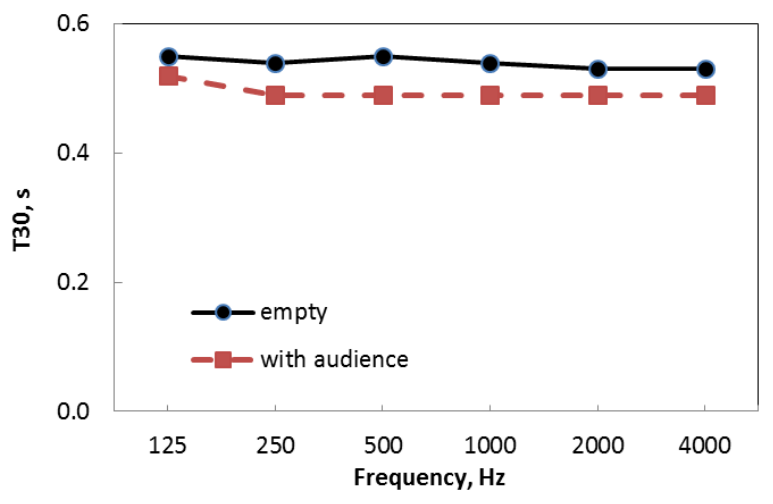

Figure 6 A. Theatre of Cassino, T30 values

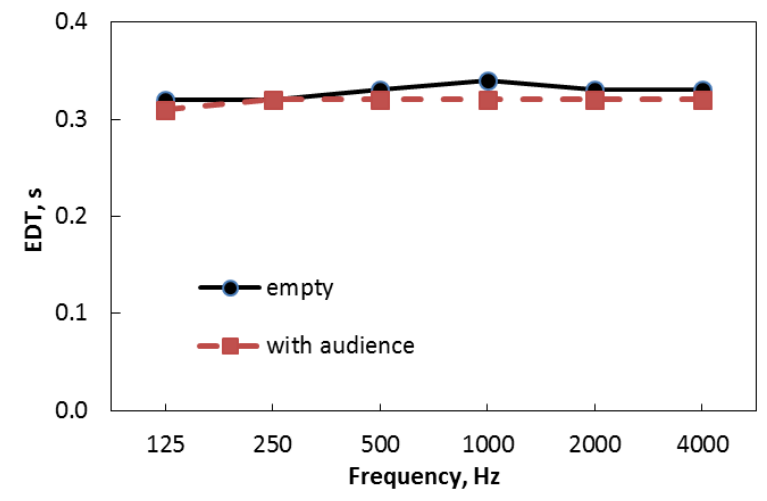

Figure 6 B. Theatre of Cassino, EDT values 


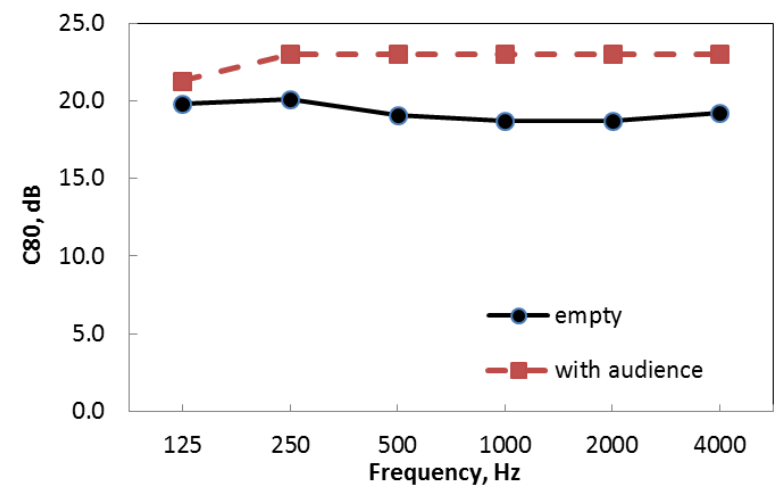

Figure $5 \mathrm{C}$. Theatre of Cassino, C80 values

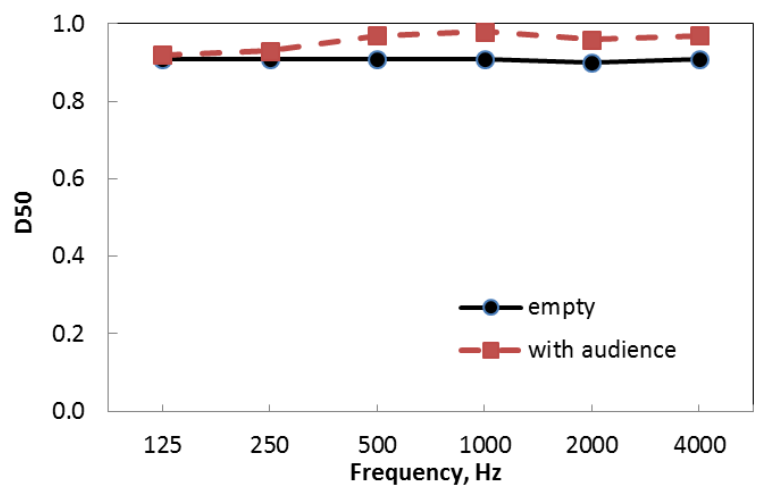

Figure $5 \mathrm{D}$. Theatre of Cassino, D50 values

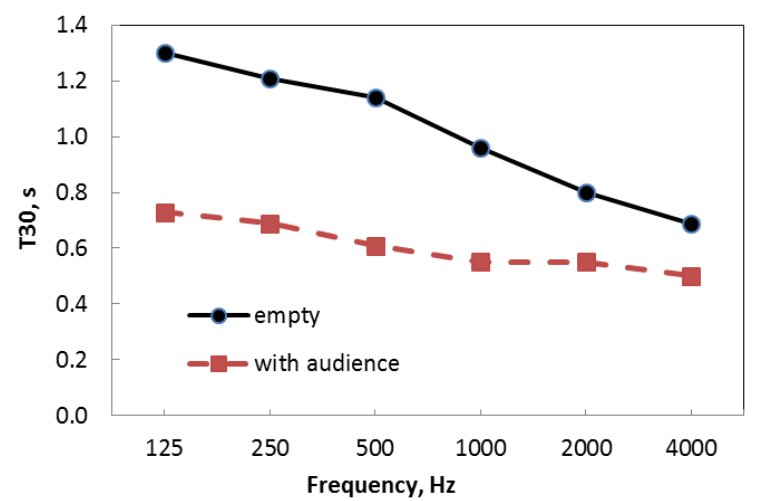

Figure $6 \mathrm{~A}$. Theatre of Taormina, T30 values

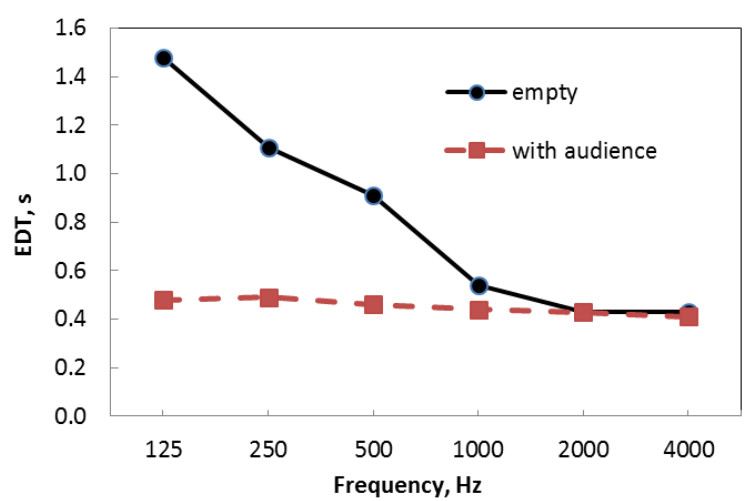

Figure 6 B. Theatre of Taormina, EDT values

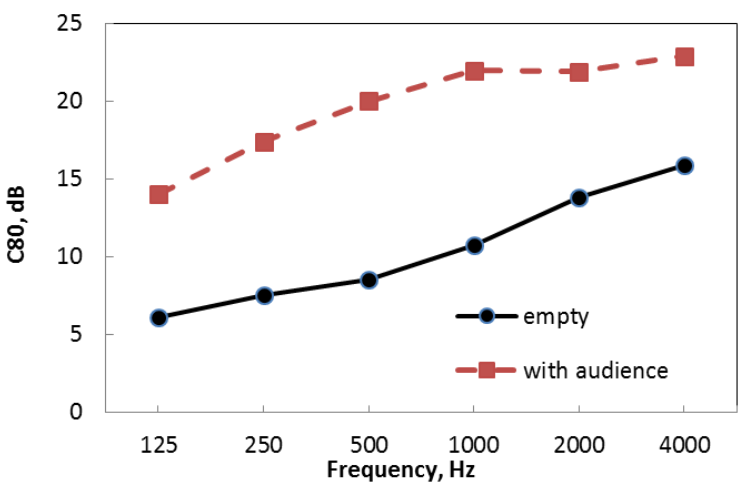

Figure $6 \mathrm{C}$. Theatre of Taormina, $\mathrm{C}_{80}$ values

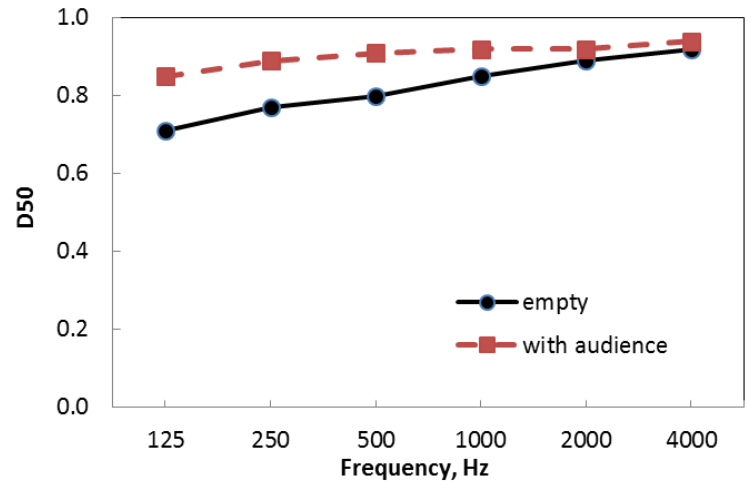

Figure $6 \mathrm{D}$. Theatre of Taormina, $D_{50}$ values

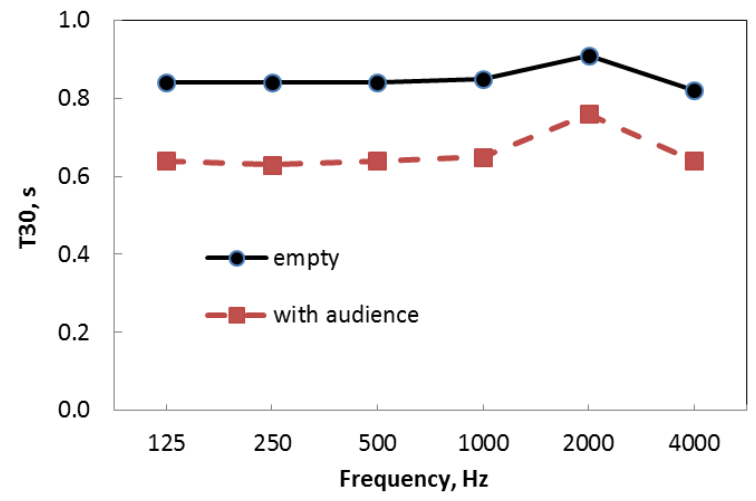

Figure $7 \mathrm{~A}$. Theatre of Pompeii, $\mathrm{T}_{30}$ values

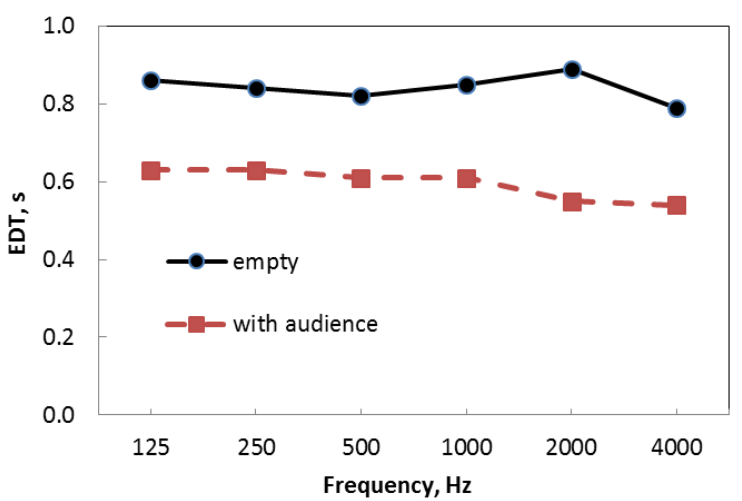

Figure 7 B. Theatre of Pompeii, EDT values 


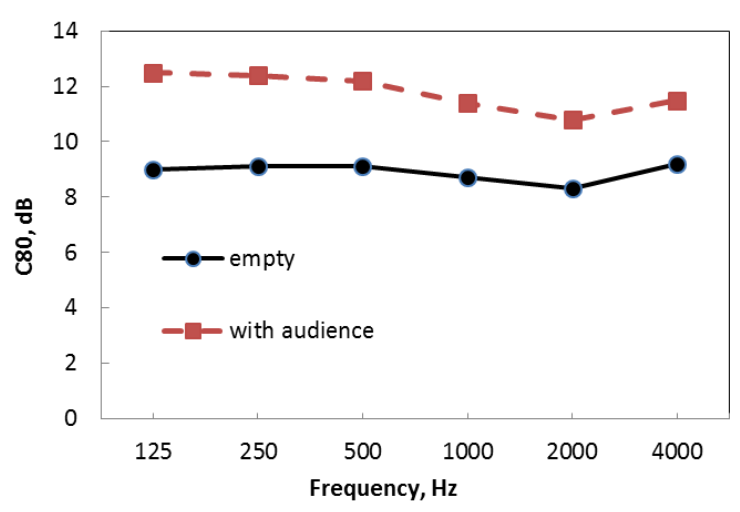

Figure $7 \mathrm{C}$. Theatre of Pompeii, $\mathrm{C}_{80}$ values

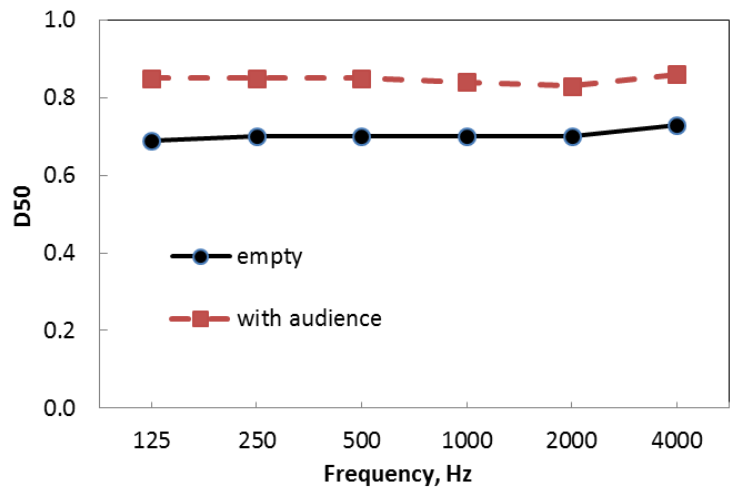

Figure $7 \mathrm{D}$. Theatre of Pompeii, $D_{50}$ values

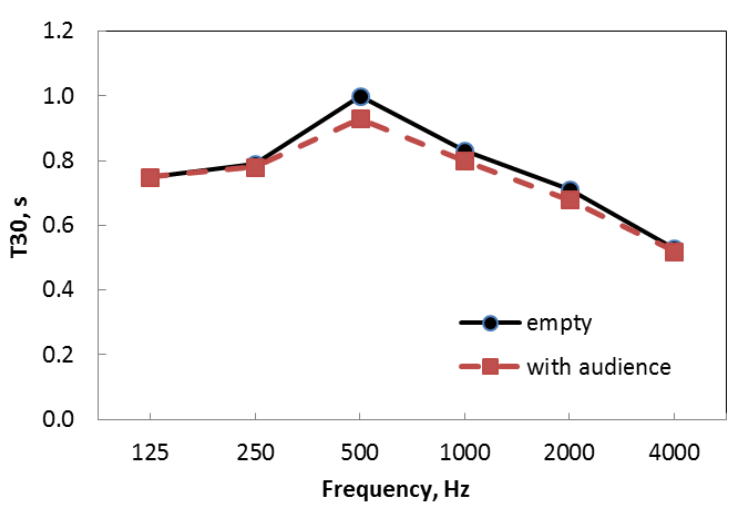

Figure 8 A. Theatre of Benevento, $T_{30}$ values

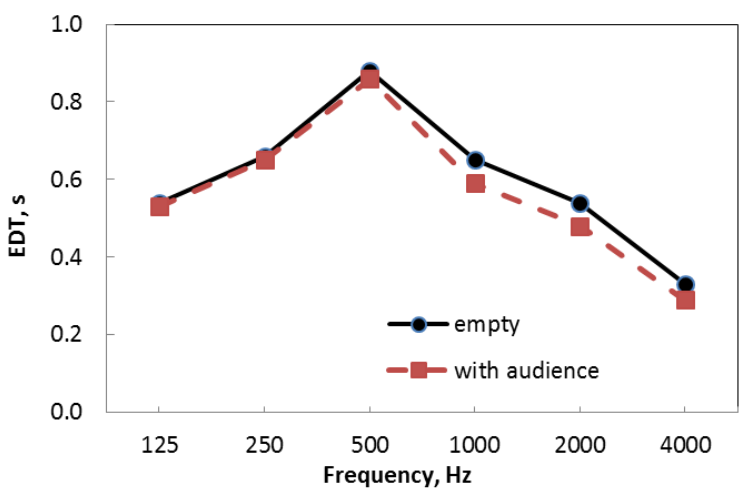

Figure 8 B. Theatre of Benevento, EDT values

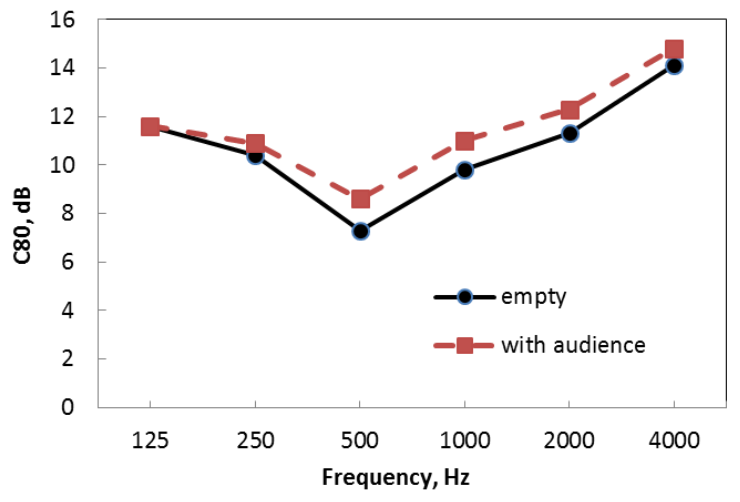

Figure $8 \mathrm{C}$. Theatre of Benevento, $\mathrm{C}_{80}$ values

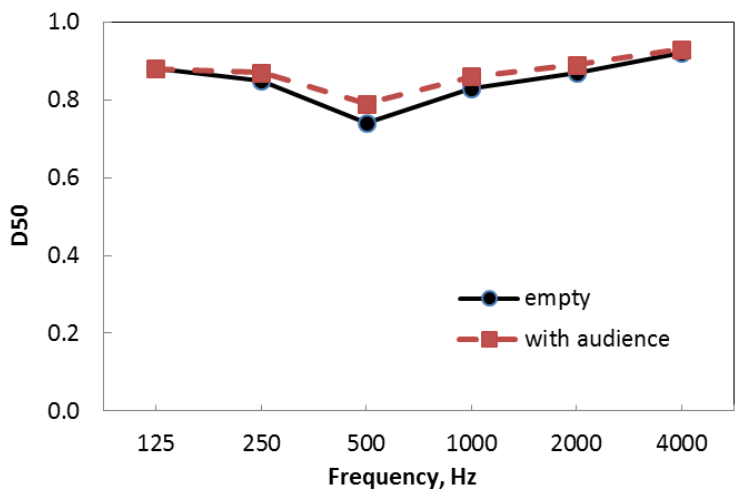

Figure $8 \mathrm{D}$. Theatre of Benevento, $\mathrm{D}_{50}$ values 


\subsection{CONCLUSION}

For the theatres of Cassino and Benevento the presence of the audience does not vary substantial variations of the acoustic characteristics. For the theatre of Cassino the absence of the stage building walls makes the acoustics poor. The analysis of the numerical simulations shows that the influence of the audience on the acoustics of theatres varies depending on the geometry of the theatre, and by the fraction of area of the cavea occupied by the audience. For the theatres of Taormina and Pompeii the presence of the audience there is a depletion of the energy in the first part of the impulse response especially at low frequencies, in fact the EDT values are very low. The analyzed theatres have an acoustics equal to that of other ancient theatres with a similar state of preservation whose main features are the clarity and the scarcity of the reverberating reflected field, so the live music of a symphony or classical orchestra or of a soloist it is not enough supported by the acoustics of these theatres.

\section{References}

[1] Ciancio Rossetto. P. and Sartorio. G. P. 1994 Greek and Roman Theatres: At the Oriains of the Represented Language. Analytical Census, Turin, Seat. 3.

[2] Izenour, G. C. 1977. Theatre Design. New York: McGraw-Hill.

[3] Sear, F. B. 1993. The Scaenae Frons of the Theater of Pompey. American J. of Archaeology. 97(4): 687-670.

[4] Iannace, G. and Trematerra, A. 2017. The Audience Effect on the Acoustics of Ancient Theatres in Modern Use. 142nd Audio Engineering Society International Convention, AES 2017 Berlin; Germany; 20-23 May, Code 128875.

[5] Beranek, L. L. and Hidaka, T. 1998. Sound Absorption in Concert Halls by Seats, Occupied and Unoccupied, and by the Hall's Interior Surfaces. Journal of the Acoustical Soc. of America. 104(6): 3169-3177.

[6] Bradley, J. S. 1996. The Sound Absorption of Occupied Auditorium Seating. Journal of the Acoustical Soc. of America. 99(2): 990-995.

[7] Zeng X., Christensen C. L. and Rindel J. H. 2006. Practical Methods to Define Scattering Coefficients in a Room Acoustics Computer Model. Applied Acoustics. 67: 771-786.

[8] Christensen, C. L. ODEON, Room Acoustics Software version 11 manual. URL: www.odeon.dk J. $\mathrm{H}$.

[9] Rindel, J. H. 2013. Roman Theaters and the Revival of Their Acoustics in the ERATO Project. Acta Acustica. 99: 21-29

[10] Trematerra A., Paternuosto S. and Lombardi I. 2017. Numerical Simulations for Acoustic Improvement of Roman Theatre of Cassino. 16th Conference on Applied
Mathematics, APLIMAT 2017-Proceedings. Bratislava; Slovakia; Code 131656.

[11] lannace, G., Evola, G., Giallo, G., Marletta, L. and Sicurella, F. 2010. The Acoustic Characteristics of the Greek - Roman Theatre of Taormina through Experimental Measurements and Numerical Simulations. Proc. of 37 National Conference of the Italian Association of Acoustics. Siracusa (Italy), 26-28 May 2010.

[12] Mau, A. 1902. Pompeii Its Life and Art. The Macmillann Company, London

[13] lannace, G. and Trematerra, A. and Masullo, M., 2013. The Large Theatre of Pompeii: Acoustic Evolution. Building Acoustics. 30(3): 215-227. DOI: 10.1260/1351-010X.20.3.215.

[14] Iannace, G. and Trematerra, A. 2013. The Rediscovery of Benevento Roman Theatre Acoustics. Journal of Cultural Heritage. 15(6): 698-703. DOI http://dx.doi.org/10.1016/j.culher.2013.11.012.

[15] lannace, G. and Berardi, U. 2017. Acoustic Virtual Reconstruction of the Roman Theater of Posillipo, Naples. Proceedings of Meetings on Acoustics. 30(1): article number 015011. DOI: 10.1121/2.0000607.

[16] Berardi, U., lannace, G. and Maffei, L. 2015. Virtual Reconstruction of the Historical Acoustics of the Odeon of Pompeii. Journal of Cultural Heritage. DOI: 10.1016/j.culher.2015.12.00.

[17] Trematerra, A., Paternuosto, S. and Lombardi, I. 2017. Virtual Reconstruction and Sound Field Simulation of the Odeon of Posillipo. $16^{\text {th }}$ Conference on Applied Mathematics, APLIMAT 2017-Proceedings. Bratislava; Slovakia;

[18] Rindel, J. H., Gade, A. C. and Lisa, M. 2006. The Virtual Reconstruction of the Ancient Roman Concert Hall in Aphrodisias, Turkey. Proc. of the Institute of Acoustics. 28. Pt. 2, 316-323.

[19] Vorländer, M. 2013. Computer Simulations in Room Acoustics: Concepts and Uncertainties. J. Acoust. Soc. Am. 133(3): 1203-1213.

[20] Vitruvio M.P. De Architectura.

[21] Iannace, G. 2016. Acoustic Correction of Monumental Churches with Ceramic Material: The Case of the Cathedral of Benevento (Italy). J. of Low Frequency Noise Vibration and Active Control. 19: 35(3), 230-239. DOI:10.1177/0263092316661028.

[22] Berardi, U. 2014. Simulation of Acoustical Parameters in Rectangular Churches. Journal of Building Performance Simulation. 7(1).

[23] Lokki, T., Southern, A., Siltanen, S., and Savioja, L. 2013. Acoustics of Epidaurus - Studies with Room Acoustics Modelling Methods. Acta Acustica. 99: 40-47.

[24] Dalenbäck, B-I. and Svensson, U. P. 2007. A Prediction Software Interface for Room Acoustic Optimization. Proc. of the 19th International Congress on Acoustics ICA 2007, Madrid.

[25] Berardi, U., Iannace, G. and Ianniello, C. 2015. Acoustic Intervention in a Cultural Heritage: The Chapel of the Royal Palace in Caserta, Italy. Buildings. 6(1). DOI: 10.3390/buildings6010001. 